\title{
Mechanical ventilation with the esophageal tracheal combitube (ETC) in the intensive care unit
}

\author{
M. FRASS, R. FRENZER, G. MAYER, R. POPOVIC AND \\ C. LEITHNER
}

Second Department of Medicine, Intensive Care Unit, University of Vienna, Austria

\section{SUMMARY}

Mechanical ventilation in critically ill patients is usually performed with the conventional endotracheal airway. The esophageal tracheal combitube (ETC) is a new device for cardiopulmonary resuscitation, conceived to bridge the gap between hospital and prehospital phases. The ETC may be used in esophageal and endotracheal positions. The authors report six patients who were ventilated with the ETC in the esophageal obturator position for 2-8h after emergency ventilation. Blood gas data showed adequate ventilation with the ETC during the observation period. Data suggest that mechanical ventilation with the ETC is possible for several hours after cardiopulmonary resuscitation. This might be helpful during the initial post-arrest period, when replacement of the ETC by a conventional endotracheal airway might destabilize a vulnerable patient.

\section{INTRODUCTION}

Mechanical ventilation in critically ill patients is usually performed with the endotracheal airway. Under certain circumstances, endotracheal intubation may be difficult. Besides different aids for endotracheal intubation, alternative methods have been described. Most known are the esophageal obturator airway (Don Michael et al., 1968; Don Michael \& Gordon, 1980) and the pharyngeo-tracheal lumen airway (Niemann et al., 1984). The esophageal obturator airway has been criticized because of insufficient face-mask seal and inadvertent tracheal insertion causing complete airway obstruction. The pharyngeo-tracheal lumen airway is surrounded by an oral cuff for upper-airways sealing. The semi-rigid stylet ensures correct shaping which has to be removed when the trachea is entered. The short lumen allows a test 'obturator' ventilation before assuming successful endotracheal intubation.

Correspondence: Dr M. Frass, 2nd Department of Medicine, ICU. University of Vienna, Garnisongasse 13, A-1090 Vienna, Austria. 
A new airway, the esophageal tracheal combitube (ETC) allows esophageal of tracheal placement. The ETC has been evaluated during routine surgery (Frass et al. 3 1987a) as well as during cardiopulmonary resuscitation (Frass et al., 1987b). Emergencyo intubation is the primary aim of the ETC. To gain experience with the ETC during mechanical ventilation after cardiopulmonary resuscitation, the authors used it inf critically ill patients for up to $8 \mathrm{~h}$. Patient characteristics and blood gas data are presented.

\section{METHODS}

The ETC (Sheridan Catheter Corporation, Argyle, New York, USA) is a double lumen tube (Frass et al., 1987a,b). One lumen may be used for esophageal obturator ventilation; it is perforated proximally and closed distally (Fig. 1). The second lumen may be used for endotracheal ventilation; it has a distal open end. Proximal to the perforations, the ETC is surrounded by a pharyngeal balloon which is filled with $100 \mathrm{mb}$ of air after insertion. The distal cuff is designed for sealing either the esophagus or thetrachea.

In most cases of blind insertion, esophageal position is obtained. Therefore, it is advisable to attach the bag-valve to the (longer) connector of the so-called 'esophageal? lumen. Air is blown through the perforations into the pharynx and from there beyond the epiglottis into the trachea. The pharyngeal balloon and the distal cuff prevent toge escape of air through mouth, nose and esophagus, respectively.

When using the esophageal lumen, failure to hear breath sounds in the lungs a⿳亠口冋口巾 auscultation of gastric insufflation mean endotracheal insertion of the ETC. The bag -5 valve must be changed immediately to the (shorter) connector of the 'tracheal' lumen. The position of the ETC remains unchanged. Ventilation occurs through the trachea lumen directly into the trachea. The distal cuff seals the trachea.

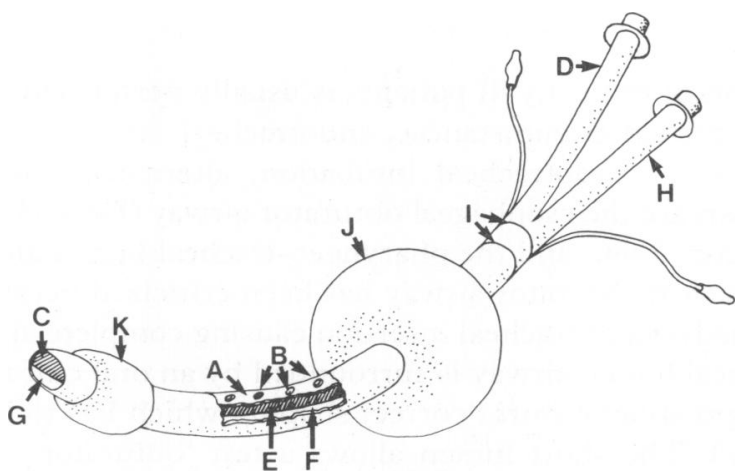

Fig. 1. Esophageal tracheal combitube (ETC): (A) 'esophageal' lumen; (B) perforations of lumen A; (c) distal closed end of lumen A; (D) longer connector for lumen A; (E) partition wall; (F) 'tracheal' lumen; $(G)$ distal open end of lumen $F$; $(H)$ shorter connector for lumen $F$; (I) printed ringmarks indicating depth of insertion; (J) pharyngeal balloon; $(\mathrm{K})$ distal cuff. 


\section{PATIENTS}

During a 3-month period ending in November 1986, six patients were ventilated on the intensive care unit with the ETC in the esophageal position following emergency intubation. The indications for using the ETC were cardiopulmonary resuscitation on the general ward (3), failure of conventional endotracheal intubation (2) and impeded vocal cord visualization due to massive regurgitation (1). Within $20 \mathrm{~min}$ after intubation, the four patients who underwent cardiopulmonary resuscitation on the general ward were transported to the intensive care unit. The patients were ventilated with a respirator (Servo 900C, Siemens, Elema, Sweden) at an average tidal volume of $12 \mathrm{ml} /$ $\mathrm{kg}$ body weight; frequency of ventilation and fractional inspired oxygen, as well as positive end-expiratory pressure, were individually adjusted. I:E-ratio was 1:2 in all patients. Patients characteristics are summarized in Table 1.

After ventilation for 2-8 h, the ETC was replaced by a conventional endotracheal airway (Mallinckrodt Lab. Ltd, Athlone, Ireland). Blood gas analyses (ABL 2 Radiometer, Copenhagen, Denmark) were recorded $15 \mathrm{~min}$ after beginning mechanical ventilation with the ETC and every hour subsequently until replacement of the ETC by a conventional endotracheal airway, as well as $15 \mathrm{~min}, 1$ and $2 \mathrm{~h}$ thereafter. The ventilatory parameters were not changed between the last hour of ETC-ventilation and the first $15 \mathrm{~min}$ of endotracheal airway ventilation. Glycopyrroniumbromide was administered to two patients, to reduce bronchial secretions.

Intubation with the ETC was performed by the physician on duty (first year resident). Replacement with an endotracheal airway was done by the chief resident.

The study was approved by the Ethical Commission of the University of Vienna.

Table 1 Patients characteristics*

\begin{tabular}{|c|c|c|c|c|c|}
\hline Patient & Age & Sex & Diagnosis & $\begin{array}{l}\text { Indication for use of } \\
\text { ETC }\end{array}$ & $\begin{array}{l}\text { Final } \\
\text { outcome }\end{array}$ \\
\hline 1 & 73 & m & $\begin{array}{l}\text { Coronary heart disease, } \\
\text { ventricular fibrillation }\end{array}$ & CPR at the general ward & Survived \\
\hline 2 & 50 & f & $\begin{array}{l}\text { Gastric cancer, skeletal } \\
\text { metastases, asystole }\end{array}$ & CPR at the general ward & Died \\
\hline 3 & 65 & $\mathrm{f}$ & $\begin{array}{l}\text { Acute respiratory distress } \\
\text { syndrome due to septic } \\
\text { shock }\end{array}$ & $\begin{array}{l}\text { Failure of endotracheal } \\
\text { intubation at the ICU }\end{array}$ & Died \\
\hline 4 & 74 & m & $\begin{array}{l}\text { Hip endoprosthesis, acute } \\
\text { respiratory failure }\end{array}$ & CPR at the general ward & Survived \\
\hline 5 & 48 & m & $\begin{array}{l}\text { Kidney transplantation, } \\
\text { cytomegalovirus infection, } \\
\text { acute respiratory failure }\end{array}$ & $\begin{array}{l}\text { Impeded visualization of } \\
\text { the vocal cords due to } \\
\text { massive regurgitation }\end{array}$ & Survived \\
\hline 6 & 68 & m & $\begin{array}{l}\text { Coronary heart disease, } \\
\text { aortocoronary bypass } \\
\text { surgery, ventricular } \\
\text { fibrillation }\end{array}$ & $\begin{array}{l}\text { Failure of endotracheal } \\
\text { intubation at the general } \\
\text { ward }\end{array}$ & Survived \\
\hline
\end{tabular}

*CPR: cardiopulmonary resuscitation; ICU: intensive care unit. 


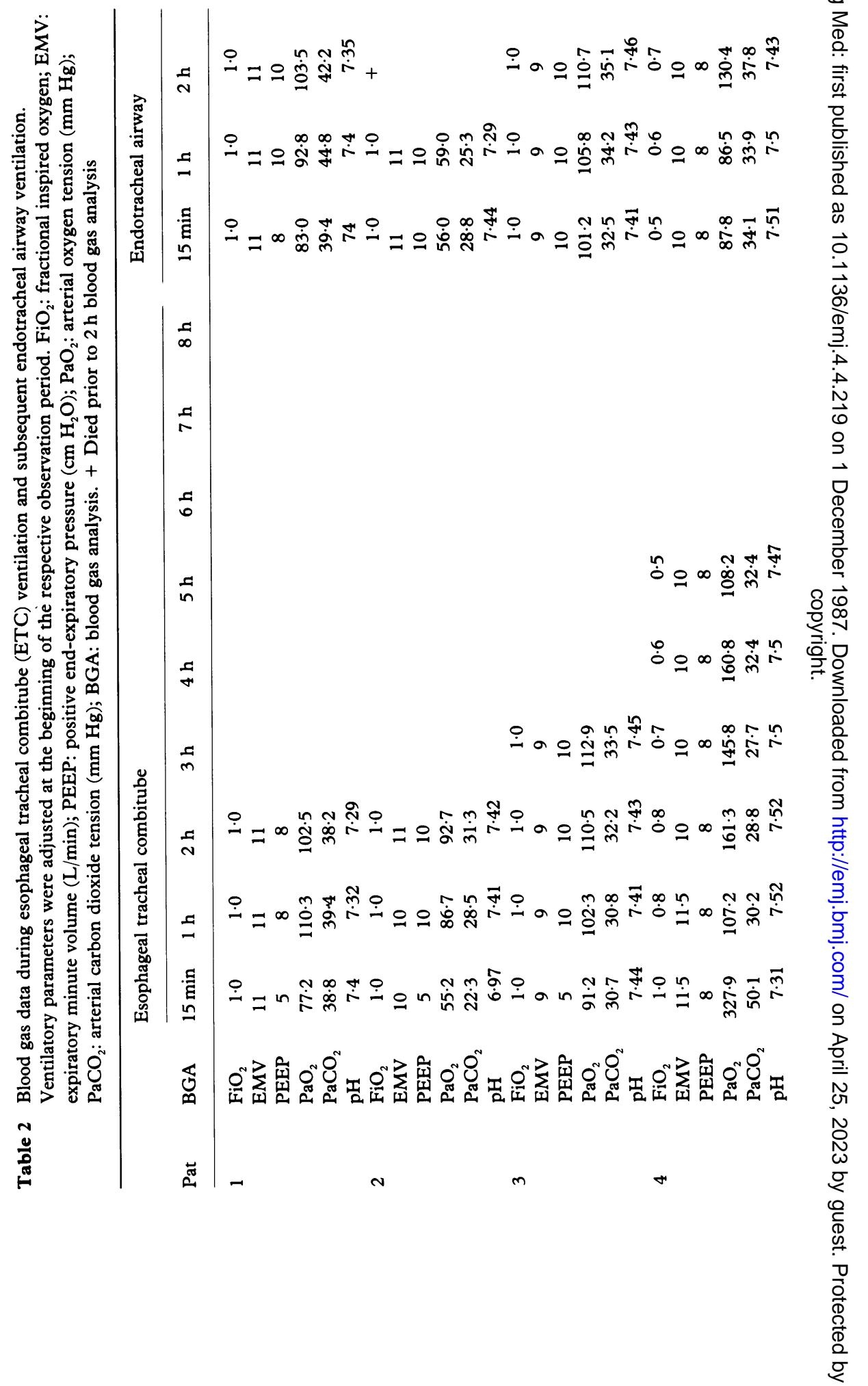




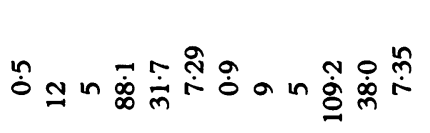

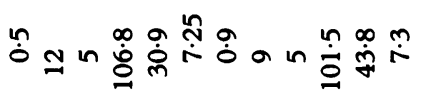

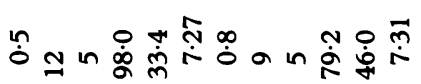

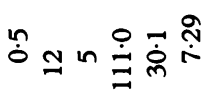

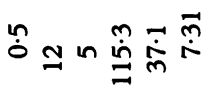

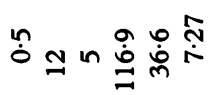

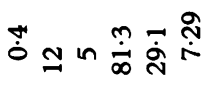

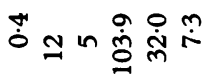

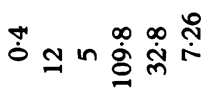

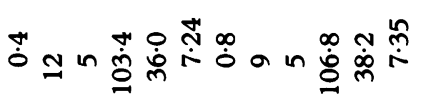

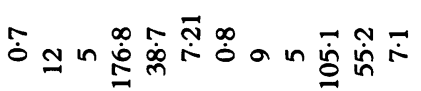

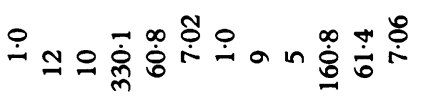

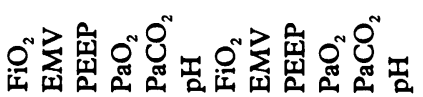




\section{RESULTS}

Prompt insertion of the ETC was possible and resulted in the esophageal position in a six patients. The patients were ventilated with the ETC in the esophageal position for 2-8 h. Blood gas data during ETC ventilation and subsequent endotracheal airway ventilation are shown in Table 2 . The blood gas data showed adequate ventilation wit the ETC during the observation period. Blood gas analysis of the last hour of ET ventilation and first $15 \mathrm{~min}$ of endotracheal airway-ventilation showed similar resul while ventilatory parameters remained unchanged.

\section{DISCUSSION}

The early establishment of a patent airway and adequate ventilation are majof determinants of successful resuscitation in acutely ill or injured patients. The bestै method is endotracheal intubation. However, endotracheal intubation requires training and the opportunity to continually maintain this skill.

The EOA is frequently used in the prehospital setting (Shea et al., 1985; Hammar gren et al., 1985; Hoflehner et al., 1984), but its use and effectiveness have bee criticized recently (Auerbach \& Geehr, 1983; Smith et al., 1983). Many perceived EO扁 problems are due to poor mask fit (White, 1984), inadvertent tracheal intubatioñ (Bryson et al., 1978) and esophageal or gastric rupture (Hoffman et al., 1983).

The ETC was designed to overcome these disadvantages. The pharyngeal ballon instead of the face-mask seals the upper airways and the two-tube system allow ventilation in either esophageal or tracheal position (even if the position is unrecog nized, the other lumen allows spontaneous breathing). The risk of upper gastrointestio nal rupture may be lower due to the shorter length of the ETC. A further advantage of the ETC is that head extension and neck movement are not required for insertion. This might be important in patients with cervical spine injuries.

Mechanical ventilation with the ETC is possible for up to $8 \mathrm{~h}$ after emergenc吿 intubation. Blood gas data show comparable results for ventilation with ETC and endotracheal airway. This might be helpful during the initial post-arrest period, whe replacement of the ETC by a conventional endotracheal airway might be difficulig Replacement can be postponed until the patient's condition has stabilized.

This study confirms earlier reports (Frass et al., 1987a,b) of effective ventilation during both routine surgery and cardiopulmonary resuscitation. The authors suggesf the following indications for use of the ETC: cardiopulmonary resuscitation by medical staff not trained in endotracheal intubation; failure of conventional endotrachea intubation (Tunstall \& Geddes, 1984); massive regurgitation or haemorrhage; inade quate access to the oropharynx; cervical spine injury; and surgery in rheumatoid arthritis with subluxation of the atlantoaxial joint.

In the authors' opinion, the ETC serves as a simple airway, especially suitable for the्ट prehospital phase. However, during in-hospital cardiopulmonary resuscitation, the ETC can be used whenever ideal conditions, facilities and staff trained in endotracheap intubation are not immediately available. 


\section{REFERENCES}

Auerbach P. S. \& Geehr E. C. (1983) Inadequate oxygenation and ventilation using the esophageal gastric tube airway in the prehospital setting. Fournal of the American Medical Association 250, 3067-71.

Bryson T. K., Benumof J. L. \& Ward C. F. (1978) The esophageal obturator airway: a clinical comparison to ventilation with a mask and oropharyngeal airway. Chest 74, 537-9.

Don Michael T. A. \& Gordon A. S. (1980) The oesophageal obturator airway: a new device in emergency cardiopulmonary resuscitation. British Medical fournal 281, 1531-4.

Don Michael T. A., Lambert E. H. \& Mehran A. (1968) 'Mouth-to-lung airway' for cardiac resuscitation. Lancet ii, 1329.

Frass M., Frenzer R., Rauscha F., Weber H., Pacher R. \& Leithner C. (1987a) Evaluation of esophageal tracheal combitube in cardiopulmonary resuscitation. Critical Care Medicine 15, 609-11.

Frass M., Frenzer R., Zdrahal F., Hoflehner G., Porges P. \& Lackner F. (1987b) The esophageal tracheal combitube esophageal (ETC): preliminary results with a new airway for cardiopulmonary resuscitation. Annals of Emergency Medicine 16, 768-72.

Hammargren Y., Clinton J. E. \& Ruiz E. (1985) A standard comparison of esophageal obturator airway and endotracheal tube ventilation in cardiac arrest. Annals of Emergency Medicine 14, 953-8.

Hoffman J. R., Pietrafesa C. A. \& Urban D. J. (1983) Esophageal 'perforation following use of esophageal obturator airway (EOA). American fournal of Emerqency Medicine 1, 282-7.

Hoflehner G., Grundner H. \& Roob P. (1984) Der Ösophagusverschlußtubus, eine neue Methode zur Notfallbeatmung. Wiener Medizinische Wochenschrift 12, 305-8.

Niemann J. T., Rosborough J. P., Myers R. \& Scarberry E. N. (1984) The pharyngeo-tracheal lumen airway: preliminary investigation of a new adjunct. Annals of Emergency Medicine 13, 591-6.

Shea S. R., MacDonald J. R. \& Gruzinski G. (1985) Prehospital endotracheal airway or esophageal gastric tube airway: a critical comparison. Annals of Emergency Medicine 14, 102-12.

Smith J. P., Bodai B. I., Seifkin A., Palder S. \& Thomas V. (1983) The esophageal obturator airway: a review. Fournal of the American Medical Association 250, 1081-4.

Tunstall M. E. \& Geddes C. (1984) 'Failed intubation' in obstetric anaesthesia: An indication for use of the 'esophageal gastric tube airway'. British fournal of Anaesthesia 56, 659-61.

White R. D. (1984) Controversies in out-of-hospital emergency airway control: esophageal obstruction or endotracheal intubation? Annals of Emergency Medicine 13, 778-81. 